\title{
Aerial Rendezvous of Small Unmanned Aircraft Using a Passive Towed Cable System
}

Timothy McLain

Mechanical Engineering Department, Brigham Young University, mclain@byu.edu

Randall W. Beard

Department of Electrical Engineering, Brigham Young University

Joseph W. Nichols

Mechanical Engineering Department, Brigham Young University

Liang Sun

Deparmtnet of Electrical and Computer Engineering, Brigham Young University

Follow this and additional works at: https://scholarsarchive.byu.edu/facpub

Part of the Mechanical Engineering Commons

\section{Original Publication Citation}

Nichols, J., Sun, L., Beard, R., and McLain, T. Aerial Rendezvous of Small Unmanned Aircraft Using a Passive Towed Cable System, AIAA Journal of Guidance, Control, and Dynamics, vol. 37, no. 4, pp. 1131-1142, DOI 10.2514/1.62220, 2014.

\section{BYU ScholarsArchive Citation}

McLain, Timothy; Beard, Randall W.; Nichols, Joseph W.; and Sun, Liang, "Aerial Rendezvous of Small Unmanned Aircraft Using a Passive Towed Cable System" (2014). Faculty Publications. 1899.

https://scholarsarchive.byu.edu/facpub/1899

This Peer-Reviewed Article is brought to you for free and open access by BYU ScholarsArchive. It has been accepted for inclusion in Faculty Publications by an authorized administrator of BYU ScholarsArchive. For more information, please contact ellen_amatangelo@byu.edu. 


\title{
Aerial Rendezvous of Small Unmanned Aircraft
}

\section{Using a Passive Towed Cable System}

\author{
Joseph W. Nichols ${ }^{1}$, Liang Sun ${ }^{2}$, Randal W. Beard ${ }^{3}$, and Timothy McLain ${ }^{4}$ \\ Brigham Young University, Provo, UT, 84602, USA
}

A method for aerial rendezvous of small unmanned aircraft systems (UAS) is proposed. The system includes placing a passive towed drogue into an orbit that is suitable for a small UAS to follow, and a guidance method for use with a monocular camera mounted on the centerline of the UAS. The principle contributions of the work include a method for controlling the drogue path in moderate winds by manipulating the mothership orbit and airspeed, and a vision-based nonlinear pursuit tracking method that uses climb rate and roll commands to guide the UAS to an aerial rendezvous with the drogue. Simulation and flight test results are presented to demonstrate the suitability of these methods.

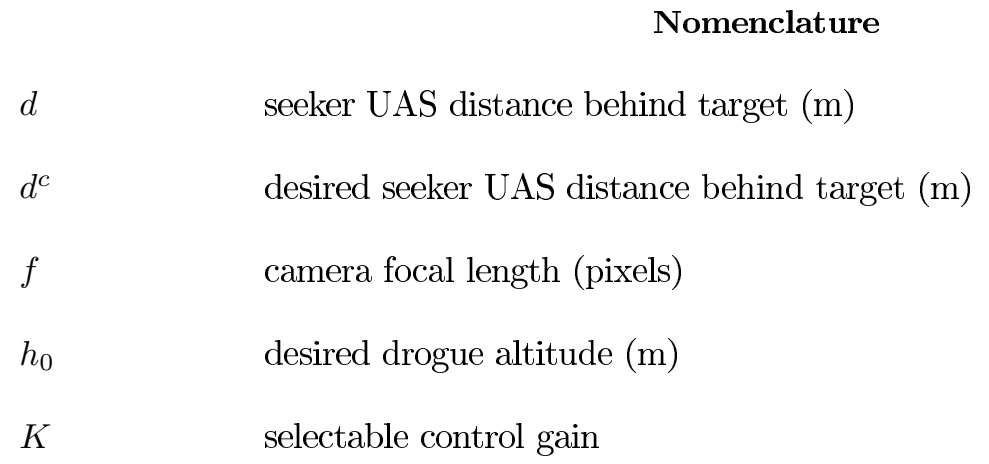

\footnotetext{
${ }^{1}$ PhD Student, Mechanical Engineering, 290 FB, Brigham Young University, Provo, UT 84602, USA; nichols@byu.edu, Senior Member, AIAA.

2 PhD Student, Electrical and Computer Engineering, 290 FB, Brigham Young University, Provo, UT 84602, USA; liang.sun@byu.edu.

3 Professor, Electrical and Computer Engineering, 450 CB, Brigham Young University, Provo, Utah 84602, USA; beard@byu.edu, Senior Member AIAA.

4 Professor, Mechanical Engineering, 435A CTB, Brigham Young University, Provo, Utah 84602, USA; mclain@byu.edu, Associate Fellow, AIAA.
} 


\begin{tabular}{|c|c|}
\hline $\mathbf{p}_{d r}^{d}$ & desired 3-D drogue trajectory $(\mathrm{m})$ \\
\hline$p_{d r_{d}}^{d}$ & down coordinate of desired drogue trajectory (m) \\
\hline$p_{d r_{e}}^{d}$ & east coordinate of desired drogue trajectory (m) \\
\hline$p_{d r_{n}}^{d}$ & north coordinate of desired drogue trajectory $(\mathrm{m})$ \\
\hline$r_{d r}^{d}$ & desired radius of the drogue orbit (m) \\
\hline$V$ & airspeed $(\mathrm{m} / \mathrm{s})$ \\
\hline $\mathbf{v}_{d r}$ & drogue velocity vector in the wind frame $(\mathrm{m} / \mathrm{s})$ \\
\hline$v_{d r}^{g}$ & desired ground speed of drogue orbit $(\mathrm{m} / \mathrm{s})$ \\
\hline $\mathbf{v}_{D}$ & drogue velocity vector in the $x-z$ body frame $(\mathrm{m} / \mathrm{s})$ \\
\hline $\mathbf{v}_{S}$ & seeker velocity vector in the $x-z$ body frame $(\mathrm{m} / \mathrm{s})$ \\
\hline $\mathbf{w}$ & wind vector in NED coordinates $(\mathrm{m} / \mathrm{s})$ \\
\hline$w_{n}$ & north component of the wind $(\mathrm{m} / \mathrm{s})$ \\
\hline$w_{e}$ & east component of the wind $(\mathrm{m} / \mathrm{s})$ \\
\hline$w_{d}$ & down component of the wind $(\mathrm{m} / \mathrm{s})$ \\
\hline $\mathbf{W}$ & scalar function \\
\hline$\beta$ & longitudinal line-of-sight angle or elevation (rad) \\
\hline$\delta_{\varphi}$ & offset of the orbital angle (rad) \\
\hline$\epsilon_{i}$ & image pixels in $i$ direction in camera frame \\
\hline$\epsilon_{j}$ & image pixels in $j$ direction in camera frame \\
\hline$\eta$ & lateral line-of-sight angle or azimuth (rad) \\
\hline$\gamma$ & climb angle or flight path angle (rad) \\
\hline$\lambda$ & orbit direction variable \\
\hline$\phi$ & roll angle (rad) \\
\hline$\psi$ & heading angle (rad) \\
\hline$\rho$ & line-of-sight vector from seeker to drogue (m) \\
\hline$\rho$ & line-of-sight distance from seeker to drogue (m) \\
\hline$\theta$ & pitch angle (rad) \\
\hline$\varphi$ & orbital angle (rad) \\
\hline
\end{tabular}




\section{INTRODUCTION}

In previous papers we have addressed various aspects of the aerial recovery problem depicted in Figure 1 [1-5]. This paper presents the most significant unpublished developments from this project and for the first time presents data from a full demonstration of all components of the system.

Many small unmanned aircraft systems (UAS) have relatively short endurance and range which limits their usefulness in applications where their home station is a long distance from the area of interest. In addition, it is assumed that there is no suitable landing area near the area of interest. Providing a method for aerial rendezvous is one way to increase the utility of UAS in this circumstance. A notional system consists of a larger aircraft to transport several UAS to the area of interest, launch them, and subsequently autonomously retrieve them by deploying a high-drag drogue that allows the smaller UAS to match the angular velocity of the mothership, while at a much lower airspeed. The smaller UAS that attempt to rendezvous with the drogue are referred to as the seeker throughout this work. The seeker would autonomously dock with the drogue which could then be reeled into the mothership. The methods developed for autonomous aerial rendezvous are important for UAS air-to-air refueling, hunter/killer UAS and other applications where it is necessary for the vehicles to make contact while airborne. This paper develops methods for commanding a UAS to follow an airborne drogue and subsequently autonomously close the distance gap and rendezvous with the drogue.

In the past decade several publications investigated strategies for retrieval of UAS. Some of the proposed solutions included parachute systems, vertical takeoff and landing systems, and ship-based retrieval systems [6-8]. However, one of the central assumptions of the problem statement is that landing near the area of interest is not possible. However, we are not aware of any publications that have addressed the scenario of retrieving UAS using aerial systems. The approach taken in this work is to employ a drogue towed by a flexible cable attached to a mothership, as shown in Figure 1. 


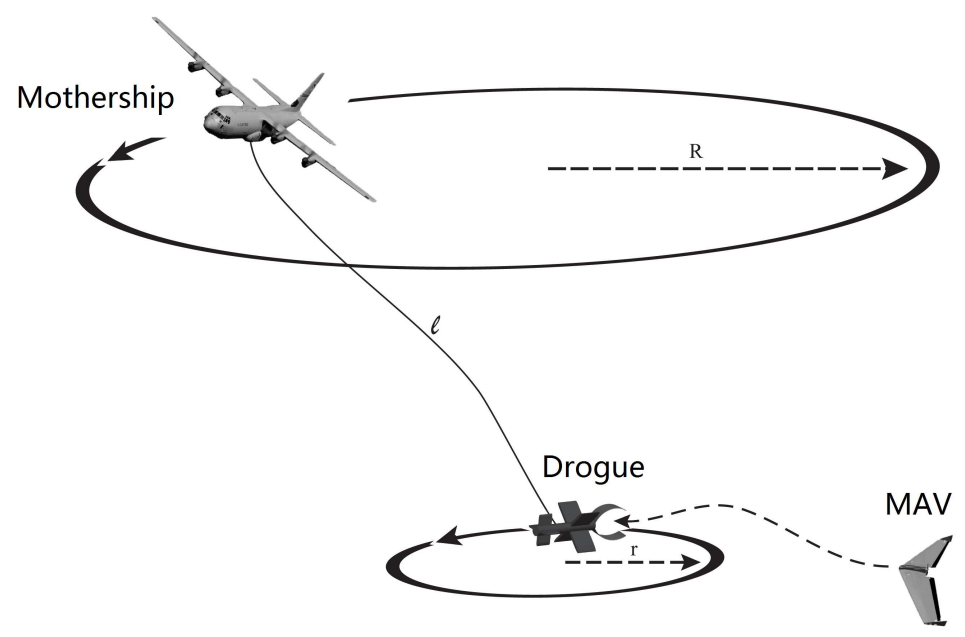

Fig. 1 Aerial recovery concept. The mothership tows a drogue that is pulled into an interior orbit to facilitate UAS-drogue docking.

The minimum velocity of the mothership is assumed to be much faster than the maximum velocity of the UAS which necessitates a flexible cable system that will place the drogue in an orbit inside the mothership orbit and at a velocity achievable by the UAS.

The system shown in Figure 1 is a notional circularly towed cable-body system. Bernoulli (1700-1782) and Euler (1707-1783) were among the first to develop dynamic solutions for whirling string systems. In more recent times, the studies of towed cable systems mainly focused on the stability and equilibrium analysis $[9,10]$ and mathematical modeling $[11,12]$. In the past decade, control strategies for towed cable systems have received renewed interest. The typical strategies for controlling the motion of the towed body include towed body active control [13-15], cable length regulation [16-18], and towing vehicle maneuvering [19-22]. For control strategies using towedbody active control and cable length regulation, additional efforts are needed to design specific mechanisms for the towed body along with extra devices like winches. The more versatile strategy for motion control of towed cable systems is a maneuverable towed vehicle. An actively controlled drogue was designed and flight tested as part of this research, but the vehicle was never mature enough to test with the entire aerial recovery system [23]. Therefore, only rendezvous techniques using a passive drogue are presented in this paper.

Hover [24] studied the control strategy of dynamic positioning of a towed pipe under the sea 
by moving the towing vehicle. Both nonlinear and linear control methods were investigated. The author concluded that the parameters for the nonlinear controller could be obtained by manipulating quantities in a linear framework. Murray [19] developed an approach to determine trajectories for the towing vehicle using differential flatness [25] for a towed cable system. Williams et al. [21] employed differential flatness to produce the desired trajectory for the towing vehicle and developed a linear receding horizon control law for the towing vehicle to follow the calculated trajectory.

In this paper, the desired mothership trajectories are produced using differential flatness. In previous studies of the motion control problem for towed cable systems, cross-wind was typically assumed to be constant during the flight. However, to keep the drogue orbit horizontally level under the disturbance of cross-wind, the variation of the wind speed and direction must be taken into account during path planning. One of the contributions of this paper, is a novel motion planning strategy accounting for the wind variation. The desired trajectories of the mothership for different wind conditions are precalculated off-line and the commanded path for the mothership is updated each orbit based on the variation of the wind.

With respect to the method for controlling the seeker we have assumed a monocular camera mounted on the centerline of the UAS or seeker. Our initial attempts to fly in formation with the drogue were extensions of vector field methods developed for unmanned aircraft $[26,27]$. As we began to work with a monocular camera and GPS position data from the drogue, we drew on the work of Park, Deyst and How [28] for ideas in the development of pure pursuit guidance methods. Park, et al. developed a nonlinear pursuit method for small UAS that was shown to be equivalent to linear proportional/derivative control. Aware of other work using nonlinear visionbased control methods for UAS [29, 30], we developed a nonlinear visual pursuit method that is mathematically stable, compatible with sensor data from GPS and/or vision, and provides improved tracking performance over previous methods implemented by the authors. This novel visual pursuit algorithm is another contribution of this paper.

The body of the paper has three main sections. Section II develops drogue orbit control which includes development of a method for controlling the shape of the drogue orbit in wind by manipulating the flight path of the mothership. In Section III, we develop a nonlinear vision-based tracking 
and control method for the seeker. Finally, Section IV contains flight test results for drogue orbit control and vision-based guidance followed by results from a full system demonstration.

\section{Drogue orbit control using mothership maneuvering}

In a windless environment, given a drogue with a large aerodynamic drag coefficient, it can be demonstrated that a horizontally level orbit of the mothership drives the drogue to converge to a horizontally level orbit with a smaller radius than that of the mothership orbit. However, when wind is present, the resulting drogue orbit will be inclined in the vertical direction and has an offset in the horizontal direction, as shown in Figure 2 which illustrates the system trajectories in the presence of $4 \mathrm{~m} / \mathrm{s}$ wind from the east. It can be seen that the amplitude of the drogue's altitude oscillation was approximately $20 \mathrm{~m}$. Although the inclined elliptical orbit can be followed by the seeker, the extra effort of flying up and down increase the complexity of the control strategy. An easy-to-follow trajectory of the drogue is preferred for the seeker in the final phase of the aerial rendezvous. Therefore, a strategy for keeping the drogue orbit horizontally level in the presence of wind is needed to facilitate a successful aerial rendezvous. In this section, a trajectory generation method is introduced for the mothership to place the drogue into a horizontally level orbit in the presence of wind.

In this paper, the cable is modeled as a series of rigid links connected by end-to-end frictionless spherical joints. Detailed description for equations of motion of cable dynamics can be found in [2]. Given a desired drogue trajectory, and the fact that the mothership-cable-drogue system is differentially flat, the desired trajectory for the mothership can be derived. A detailed derivation of this method can be found in [1]. 


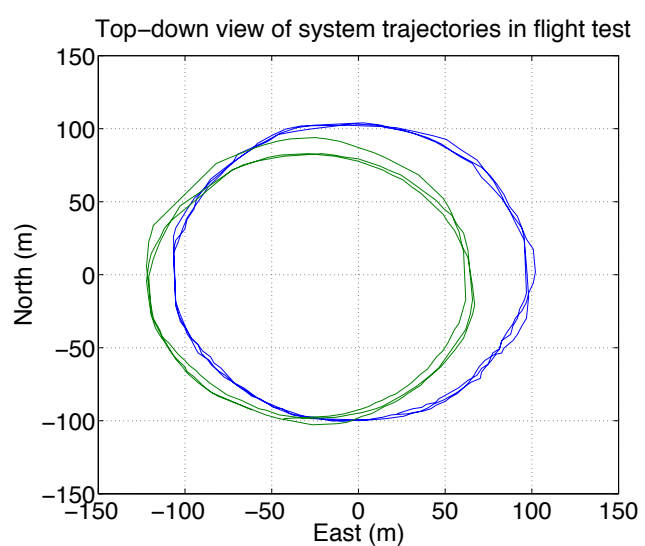

(a)

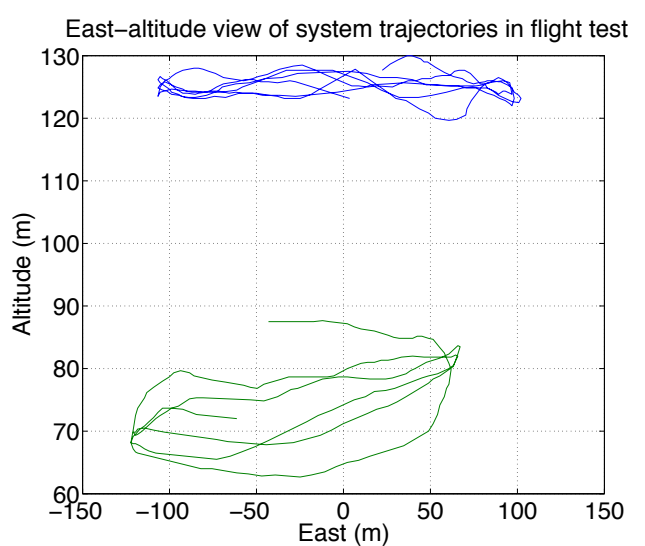

(b)

Fig. 2 System trajectories in the presence of $4 \mathrm{~m} / \mathrm{s}$ wind from the east. (a) Mothership and drogue orbits. Mothership (outer) orbit has a radius of $100 \mathrm{~m}$ at airspeed of $14 \mathrm{~m} / \mathrm{s}$ while the resulting drogue (inner) orbit has a radius of approximately $90 \mathrm{~m}$; (b) Side view, drogue (lower) orbit is inclined due to the presence of wind. The altitude oscillation is approximately $20 \mathbf{m}$.

A. Trajectory generation using a desired circular orbit of the drogue in the presence of wind

A typical drogue orbit can be used to derive the desired mothership trajectory which is a circular path. Letting $\mathbf{p}_{d r}^{d}(t) \triangleq\left(p_{d r_{n}}^{d}, p_{d r_{e}}^{d}, p_{d r_{d}}^{d}\right)^{T} \in \mathbb{R}^{3}$ be the desired position of drogue in the inertial north-east-down (NED) frame, $r_{d r}^{d}$ be the desired constant orbit radius of the drogue, $\varphi$ be the orbital angle for a clockwise motion, and $h_{0}$ be the desired constant altitude of the drogue, the desired circular trajectory of the drogue can be written as

$$
\begin{aligned}
& p_{d r_{n}}^{d}(t)=r_{d r}^{d} \cos \varphi(t) \\
& p_{d r_{e}}^{d}(t)=r_{d r}^{d} \sin \varphi(t) \\
& p_{d r_{d}}^{d}(t)=-h_{0} .
\end{aligned}
$$

Letting $\mathbf{v}_{d r}(t) \in \mathbb{R}^{3}$ be the velocity vector of the drogue in the wind frame, and $\mathbf{w}(t) \triangleq$ $\left(w_{n}, w_{e}, w_{d}\right)^{T} \in \mathbb{R}^{3}$ be the wind speed vector in the NED frame, the first and second order time 
derivatives of $\mathbf{p}_{d r}^{d}(t)$ are given by

$$
\begin{gathered}
\dot{\mathbf{p}}_{d r}^{d} \triangleq \mathbf{v}_{d r}=\left(\begin{array}{c}
-r_{d r}^{d} \dot{\varphi} \sin \varphi \\
r_{d r}^{d} \dot{\varphi} \cos \varphi \\
0
\end{array}\right) \\
\ddot{\mathbf{p}}_{d r}^{d}=\left(\begin{array}{c}
-r_{d r}^{d}\left(\ddot{\varphi} \sin \varphi+\dot{\varphi}^{2} \cos \varphi\right) \\
r_{d r}^{d}\left(\ddot{\varphi} \cos \varphi-\dot{\varphi}^{2} \sin \varphi\right) \\
0
\end{array}\right) .
\end{gathered}
$$

Thus, given desired $r_{d r}^{d}, h_{0}, \varphi(t)$, and a prediction of wind vector $\mathbf{w}$, the desired trajectory for the mothership can be derived by applying the differential flatness based strategy described in [1].

\section{B. Simulation results}

Typically, the autopilot on the mothership is designed to regulate a constant airspeed. Therefore, a desired drogue trajectory with constant airspeed is used to calculate the desired mothership orbit. The drogue airspeed, $\left\|\mathbf{v}_{d r}\right\|$, using Eq. (4) is given by

$$
\left\|\mathbf{v}_{d r}\right\|=\sqrt{\left(-r_{d r} \dot{\varphi} \sin \varphi-w_{n}\right)^{2}+\left(r_{d r} \dot{\varphi} \cos \varphi-w_{e}\right)^{2}+w_{d}^{2}}
$$

Therefore, given a desired drogue airspeed $v_{d r}^{a}$, we have

$$
r_{d r}^{2} \dot{\varphi}^{2}+2 r_{d r}\left(w_{n} \sin \varphi-w_{e} \cos \varphi\right) \dot{\varphi}+w_{n}^{2}+w_{e}^{2}+w_{d}^{2}-\left(v_{d r}^{a}\right)^{2}=0
$$

Solving the quadratic equation for $\dot{\varphi}$, the clockwise motion is given by

$$
\dot{\varphi}=\frac{w_{e} \cos \varphi-w_{n} \sin \varphi+\sqrt{\left(w_{n} \sin \varphi-w_{e} \cos \varphi\right)^{2}-\left(w_{n}^{2}+w_{e}^{2}+w_{d}^{2}-\left(v_{d r}^{a}\right)^{2}\right)}}{r_{d r}} .
$$

For the purpose of implementing the strategy of drogue orbit control, the performance limits of the mothership must be considered. Based on the current hardware, the airspeed range of the mothership was $10-20 \mathrm{~m} / \mathrm{s}$. Therefore the amplitude oscillations of desired mothership airspeeds need to remain in this range. Larger orbit radii produce lower peak airspeed requirements. Therefore, the desired orbit radius of the drogue was set so that amplitude oscillations of desired airspeeds would decrease. Figure 3 shows the results using the desired orbit radius of the drogue as $r_{d r}^{d}=250 \mathrm{~m}$. It can be seen that desired airspeeds of the mothership remain in $14-18 \mathrm{~m} / \mathrm{s}$. 


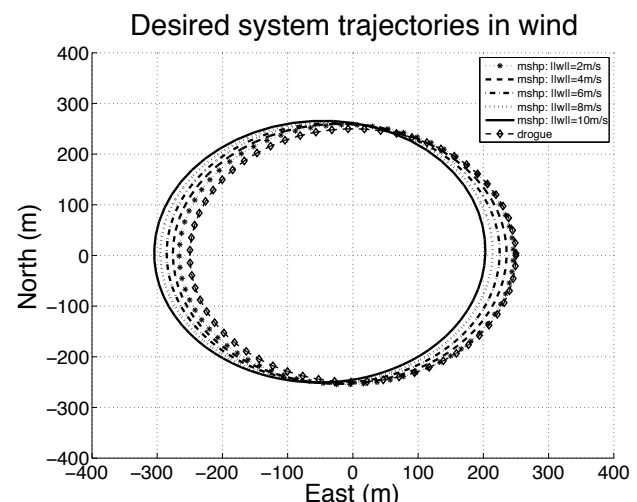

(a)

Desired system trajectories in wind

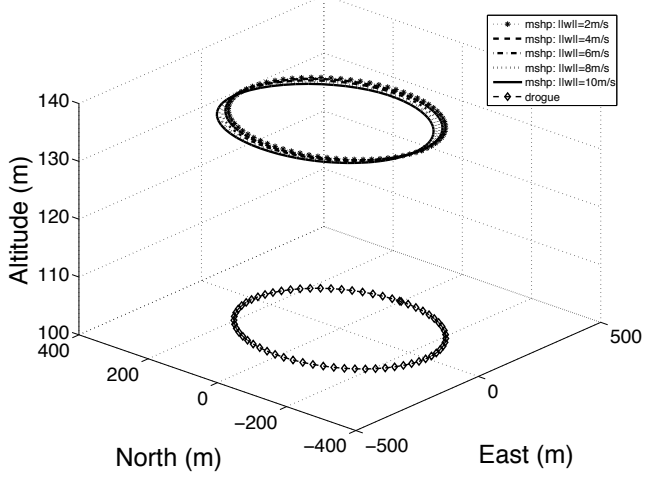

(c)

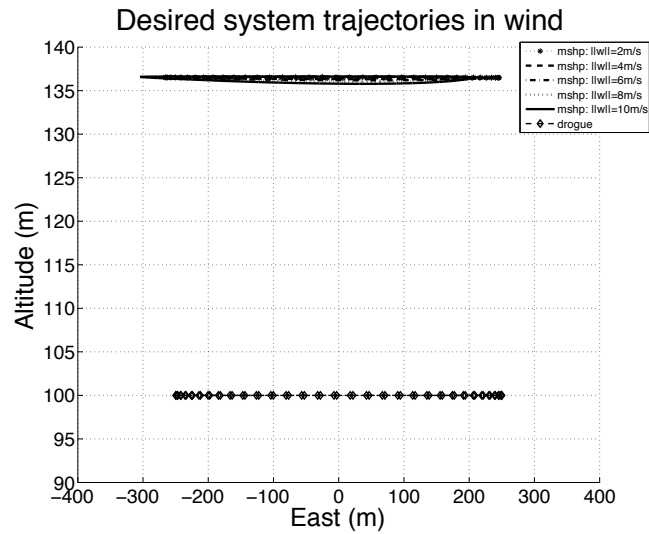

(b)

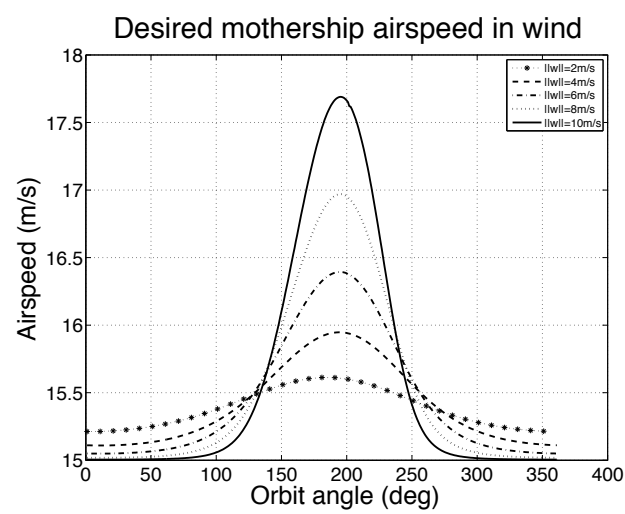

(d)

Fig. 3 Desired mothership trajectories using desired drogue orbit with constant airspeed and orbit radius $r_{d r}^{d}=250 \mathrm{~m}$ in different wind conditions. (a) Top-down view; (b) Side view; (c) Three-dimensional view; (d) Desired mothership airspeed for different wind conditions.

\section{Seeker Control}

The seeker is assumed to be equipped with a monocular camera mounted on the centerline of the vehicle and the camera is able to provide the guidance algorithm with the pixel location of the drogue in the image. A Lyapunov-based visual pursuit method that is compatible with both GPS and vision sensor data is developed in this section. The dynamics are assumed to be decoupled laterally and longitudinally.

\section{A. Coordinate Frames}

The inertial, body, camera, and line-of-sight (LOS) frames are the primary coordinate frames referenced in the development of the visual pursuit method. The frames are referenced according the convention laid out in [31]. The inertial coordinate system is an earth-fixed coordinate system 
with its origin at the defined home location. It is oriented such that north is defined as the 0 radian heading direction, east as the $\frac{\pi}{2}$ radian heading direction and the altitude reference of positive direction being down. The body frame is obtained by moving the origin to the center of mass of the seeker and then rotating the coordinate axes through the yaw or heading $\psi$, roll $\phi$, and pitch $\theta$ angles such that the $x$-axis runs from the center of mass along the centerline of the seeker and out the nose, the $y$-axis runs from the center of center of mass out the right wing perpendicular to the $x$-axis and the $z$-axis runs from the center of mass through the bottom of the seeker perpendicular to the $x$ and $y$ axes. The camera frame is located at the image plane of the camera with the axes aligned with the body frame such that the camera frame $i^{i m}$ axis is aligned with the body frame $y$-axis and $j^{i m}$ is aligned with the body frame $z$-axis as shown in Figure 4 . The LOS frame of the reference is aligned with the line-of-sight vector $\rho$ and is formed by rotating the body frame through the lateral and longitudinal azimuth $\eta$ and elevation $\beta$ angles.

\section{B. Camera Geometry}

The approach taken in this paper is to assume that the seeker has a fixed camera aligned with the longitudinal axis of the aircraft. The UAS should have an autopilot with inner control loops to command climb rate, roll angle and airspeed. Lateral commands originate with the horizontal distance of the drogue from the center of the image, while longitudinal commands derive from the vertical distance of the drogue image from the center of the image as shown in Figure 4.

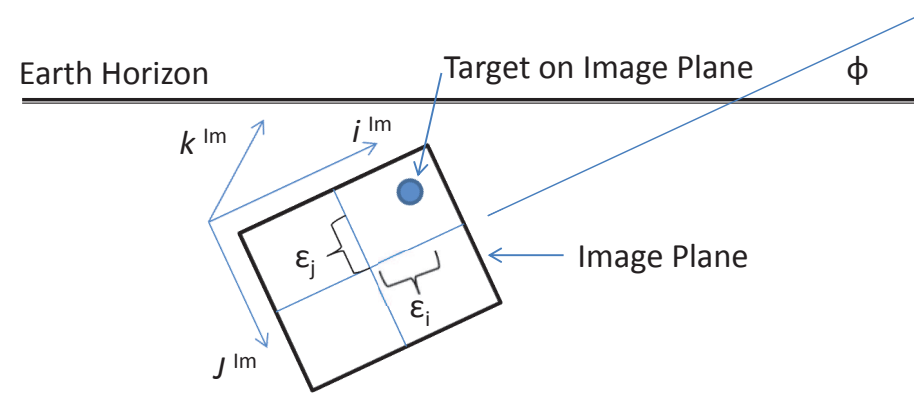

Fig. 4 Seeker camera frame. Seeker is pitched down and rolled to an angle $\phi$. The distance of the projection of the drogue on the image frame from the center of the image frame is specified by $\epsilon_{i}$ and $\epsilon_{j}$. 
Pixel distances are converted to elevation angle $\beta$ and azimuth angle $\eta$ according to

$$
\begin{aligned}
& \beta=\tan ^{-1}\left(\frac{\epsilon_{j}}{f}\right) \\
& \eta=\tan ^{-1}\left(\frac{\epsilon_{i}}{f}\right)
\end{aligned}
$$

where $f$ is the focal length of the camera.

\section{Lateral Dynamics}

The relative lateral dynamics between the seeker and the drogue are expressed in twodimensional polar coordinates with the body frame $z$-axis projected onto the body frame $x$ and $y$-axes as shown in Figure 5. It is assumed that because the seeker and drogue will be in close proximity, wind will affect the seeker and drogue equally and therefore does not factor directly in the equations of motion. Let $\rho$ be the line-of-sight vector and $\eta$ be the lateral line-of-sight angle or

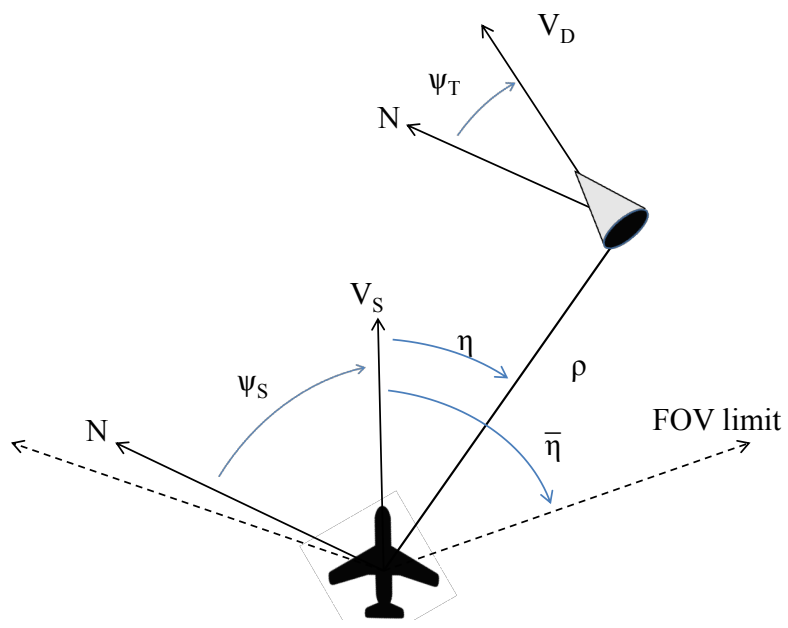

Fig. 5 Two-dimensional lateral polar coordinates of the seeker and drogue in the $x-y$ body frame. Where $\rho$ is the line-of-sight vector between the seeker and the drogue; $\eta$ is the angle between the seeker heading and the line-of-sight vector; $\bar{\eta}$ is the maximum filed-of-view angle; and the angles $\psi_{S}$, and $\psi_{T}$ are the seeker and drogue headings.

the angle between the optical axis of the seeker and the drogue. The relevant equations of motion are

$$
\dot{\psi_{S}}=\frac{g}{V_{S}} \tan \phi
$$


which is the expression for a coordinated turn, and

$$
\dot{\rho}=V_{D} \cos \left(\psi_{S}-\psi_{T}+\eta\right)-V_{S} \cos \eta
$$

is the change in the length of the line-of-sight vector, where $V_{D}$ and $V_{S}$ are the drogue and seeker airspeeds, $\psi_{T}$ and $\psi_{S}$ are the drogue and seeker heading angles, and $\phi$ is the roll angle of the seeker. The rate of change in the line-of-sight angle can be found by observing that $\dot{\eta}$ is equal to the sum of the seeker rotation rate and the tangential velocities of the ends of the line-of-sight vector. Therefore

$$
\dot{\eta}=-\dot{\psi_{S}}+\frac{V_{S}}{\rho} \sin \eta+\frac{V_{D}}{\rho} \sin \left(\eta+\psi_{S}-\psi_{T}\right) .
$$

\section{Longitudinal Dynamics}

The relative longitudinal dynamics between the seeker and the drogue are expressed in twodimensional polar coordinates with the body frame $y$-axis projected onto the body frame $x$ and $z$-axes as shown in Figure 6. Let $\mathbf{v}_{S}$ and $\mathbf{v}_{D} \triangleq\left(V_{x}^{\text {body }}, V_{z}^{\text {body }}\right)^{T} \in \mathbb{R}^{2}$. The drogue is assumed to be

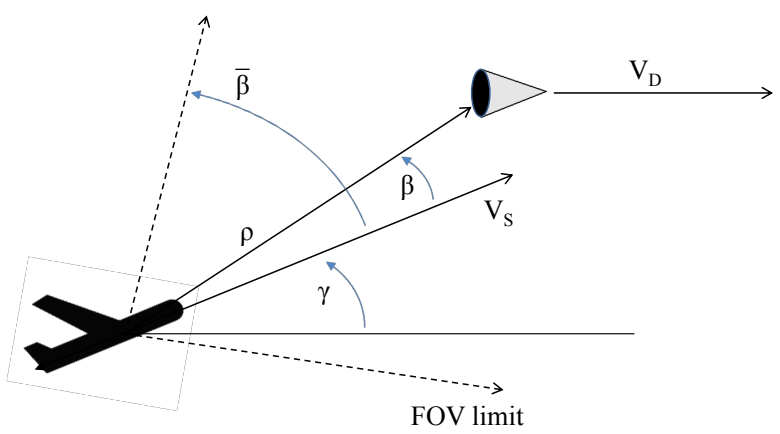

Fig. 6 Two-dimensional longitudinal polar coordinates of the seeker and drogue in the $x-z$ body frame, where $\beta$ is the angle between the seeker flight path angle $\gamma$ and the longitudinal line-of-sight vector; $\rho$ is the line-of-sight vector; and the angle $\bar{\beta}$ is the maximum filed-of-view angle. The line-of-sight frame of reference is aligned with the line-of-sight vector $\rho$.

towed at a constant altitude and constant velocity. The time rate of change of the LOS vector, $\rho$, is computed by taking the vector difference of the drogue and seeker velocities according to

$$
\dot{\rho}=\mathbf{v}_{D}-\mathbf{v}_{S},
$$


where,

$$
\begin{gathered}
\mathbf{v}_{D}=\left[\begin{array}{c}
V_{D} \\
0
\end{array}\right] \\
\mathbf{v}_{S}=\left[\begin{array}{c}
V_{S} \cos \gamma \\
V_{S} \sin \gamma
\end{array}\right] .
\end{gathered}
$$

The rotation matrix from the two-dimensional body to the line-of-sight frame is

$$
\mathbf{R}_{x-z b o d y}^{L O S}=\left[\begin{array}{cc}
\cos (\gamma+\beta) & \sin (\gamma+\beta) \\
-\sin (\gamma+\beta) & \cos (\gamma+\beta)
\end{array}\right] .
$$

In the LOS frame, the LOS vector can be expressed in terms of radial and tangential components as

$$
\begin{aligned}
\dot{\rho}^{L O S} & \triangleq\left[\begin{array}{c}
\dot{\rho}_{r} \\
\dot{\rho}_{t}
\end{array}\right], \\
\dot{\rho}^{L O S} & =\mathbf{R}_{x-z b o d y}^{L O S}, \\
& =\left[\begin{array}{c}
\dot{\rho} \\
\rho(\dot{\gamma}+\dot{\beta})
\end{array}\right] .
\end{aligned}
$$

Therefore from (10) through (15), the time rate of change in the line-of-sight vector in the tangential direction is

$$
\dot{\rho}_{t}=-\left(V_{D}-V_{S} \cos \gamma\right) \sin (\gamma+\beta)-V_{S} \sin \gamma \cos (\gamma+\beta) .
$$

By rearranging (14) and (16), and noting that the full expression for $\dot{\rho}_{t}$ can be found in (17), the time rate of change in longitudinal pointing error is found to be

$$
\dot{\beta}=\frac{\dot{\rho}_{t}}{\rho}-\dot{\gamma}
$$

\section{E. Visual Pursuit Guidance}

Our goal is to develop a guidance method that is stable about the center of the image frame. In other words we want to develop a function that produces control inputs that will drive the lateral $\eta$ and longitudinal $\beta$ line-of-sight angles to zero. Since the guidance method is an outer control loop 
that wraps around an inner autopilot control loop we must assume that the commanded control inputs $\phi^{c}$ and $\dot{\gamma}^{c}$ converge quickly to the instantaneous roll and climb rate to prove stability. It has been observed that this is a good assumption for well tuned autopilots that the commanded and actual roll and climb rates track very well. We now develop two scalar functions based on $\eta$ and $\beta$ and calculate the first derivative with respect to time. We then choose values for $\phi^{c}$ and $\dot{\gamma}^{c}$ that result in the derivatives also being functions of only $\eta$ and $\beta$ and two experimentally derived gains. By showing that the derivatives of the scalar functions are always negative when using the chosen values for $\phi^{c}$ and $\dot{\gamma}^{c}$ the control method is found to be stable.

\section{Lateral Control}

To derive a control method to keep the drogue in the lateral filed-of-view, consider the scalar function $W_{1}=\frac{1}{2} \eta^{2}$ that represents the square of the lateral pointing error. Differentiating the function with respect to time yields

$$
\begin{aligned}
\dot{W}_{1} & =\eta \dot{\eta} \\
& =\eta\left[\frac{-g}{V_{S}} \tan \phi+\frac{V_{S}}{\rho} \sin \eta-\frac{V_{D}}{\rho} \sin \left(\psi_{S}-\psi_{T}+\eta\right)\right] .
\end{aligned}
$$

By selecting the roll angle $\phi_{S}$ to be

$$
\phi^{c}=\tan ^{-1}\left[\frac{V_{S}}{g}\left(\frac{V_{S}}{\rho} \sin \eta-\frac{V_{D}}{\rho} \sin \left(\psi_{S}-\psi_{T}+\eta\right)+K_{\phi} \eta\right)\right]
$$

and substituting into (20), the scalar function becomes

$$
\dot{W}_{1}=-K_{\phi} \eta^{2}
$$

If the gain $K_{\phi}$ is chosen to be positive, $\dot{W}_{1}$ is always negative which ensures that when using (21) for $\phi^{c}$, the drogue will remain within the camera FOV [32].

\section{Longitudinal Control}

The stability of the longitudinal control method is derived in the same manner as the lateral control. Consider the scalar function $W_{2}=\frac{1}{2} \beta^{2}$ that represents the square of the longitudinal 
pointing error. Differentiating the function with respect to time yields

$$
\begin{aligned}
\dot{W}_{2} & =\beta \dot{\beta} \\
& =\beta\left(\frac{\dot{\rho}_{t}}{\rho}-\dot{\gamma}\right) .
\end{aligned}
$$

By selecting the climb rate $\dot{\gamma}$ to be

$$
\dot{\gamma}^{c}=\frac{\dot{\rho}_{t}}{\rho}+K_{\gamma} \beta
$$

and substituting into (24), the scalar function becomes

$$
\dot{W}_{2}=-K_{\gamma} \beta^{2}
$$

If the gain $K_{\gamma}$ is chosen to be positive, $\dot{W}_{2}$ is always negative which ensures that while using (25) for $\dot{\gamma}^{c}$, the drogue will remain within the camera FOV.

\section{F. Rendezvous}

The seeker commanded airspeed $V_{S}^{c}$ during the rendezvous is regulated using a linear controller with the error input being the difference between the actual and desired seeker distance behind the drogue. Proportional control is used according to

$$
V_{S}^{c}=V_{S}+K_{p}\left(d^{c}-d\right)+V_{c r}
$$

where $K_{p}$ is the proportional gain, $d^{c}-d$ the error between the desired following distance and the current distance behind the drogue, and $V_{S}$ is the current seeker airspeed and $V_{c r}$ is the closure rate (typically $2 \mathrm{~m} / \mathrm{s}$ ). Rendezvous was initiated when the seeker had a good visual track of the drogue. The visual pursuit algorithm was used to control seeker roll and climb rate during the approach to rendezvous. As the seeker approached the drogue, lateral and longitudinal gains were reduced as a function of distance to the drogue to limit large control oscillations. If the seeker sensed that it had passed the drogue it reduced its airspeed and retreated to a position $25 \mathrm{~m}$ behind the drogue prior to beginning the rendezvous attempt again.

\section{G. Simulation Results}

Simulations were conducted in Simulink using a six degree-of-freedom aerodynamic model of the seeker tracking a simulated drogue. The location of the camera image plane was calculated 
to emulate vision processing. Noise on the camera and on the GPS signal was included in the simulation. We used an emulated Kestrel autopilot with the airspeed of the drogue UAS set to $15 \mathrm{~m} / \mathrm{s}$ flying in a circular orbit with a radius of $250 \mathrm{~m}$. The altitude was varied approximately $20 \mathrm{~m}$ from a low point directly into the wind on the east and a high point directly into the wind on the west to simulate the effects of a $2 \mathrm{~m} / \mathrm{s}$ wind from the east. This produced in three-dimensions an inclined ellipse that simulated the observed behavior of the drogue in wind. The seeker was commanded to follow the drogue at a distance of $30 \mathrm{~m}$. The conditions selected for the simulation were designed to approximate the conditions anticipated during the flight trials that will be described later. The results of the visual pursuit simulation are shown in Figure 7. Roll angle and climb rate were controlled according to (21) and (25).

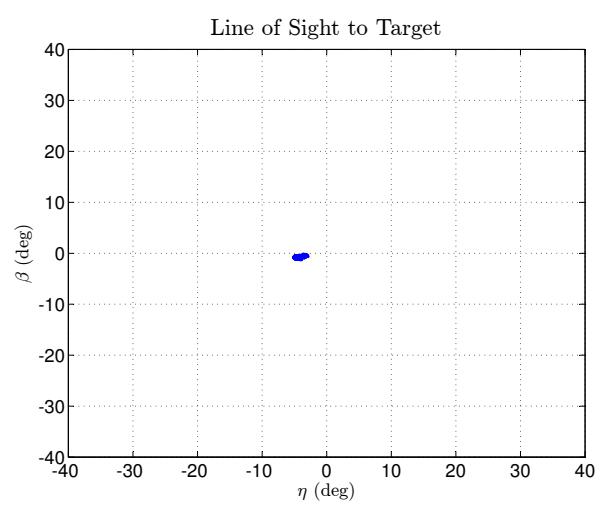

(a)

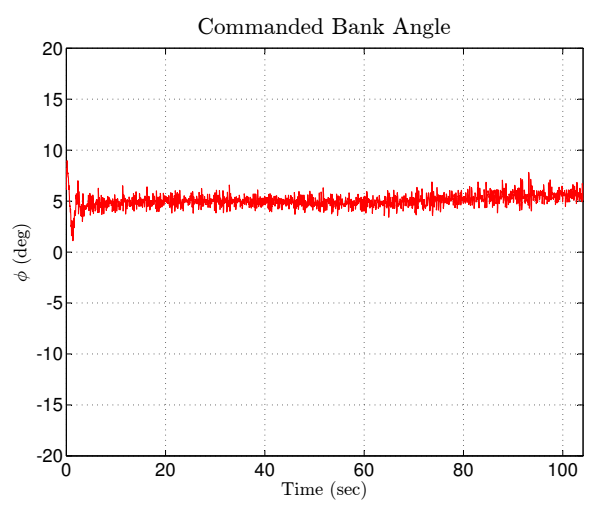

(c)

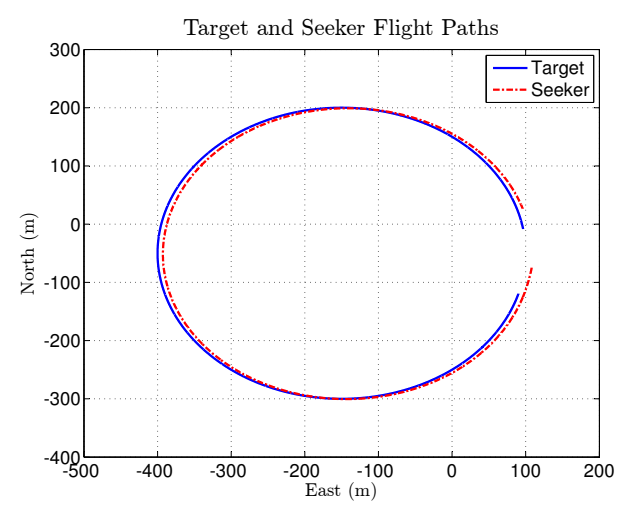

(b)

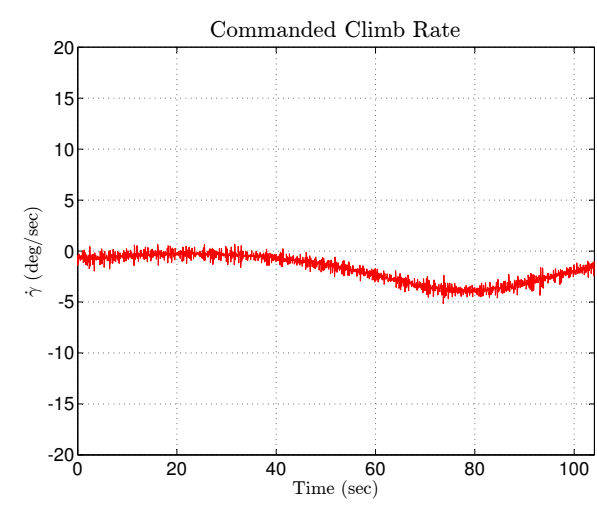

(d)

Fig. 7 Simulation results using Simulink. (a) Visual pursuit line-of-sight error to the drogue; (b) visual pursuit seeker and drogue UAS flight paths; (c) commanded roll angle; (d) commanded climb rate. 
Camera pixel locations of the target are converted to line-of-sight angles according to (5) and (6) for ease in combining with GPS data. The mean line-of-sight error for visual pursuit from the simulation was found to be $4.3 \mathrm{deg}$ with very little movement of the target in the image plane throughout the orbit as can be seen in Figure 7 (a). Figure 7 (b) shows that the seeker was able to follow closely the simulated drogue path despite significant noise on the GPS and vision data as can be observed from examining the commanded bank angle and climb rate plots shown in Figure 7 (c) and (d). Bank angle and climb rate commands were computed according to the visual pursuit method using (21) and (25). The $L_{2}$ norm of the bank angle command for the orbit was $5.0 \mathrm{deg}$ and the $L_{2}$ norm of the climb rate command was $1.8 \mathrm{deg} / \mathrm{sec}$. The simulation shows that the method is suitable for following a towed drogue around an elliptical flight path as would be required for an aerial rendezvous.

\section{Flight Trial Results}

\section{A. Hardware Platform Description}

The hardware system used to test the control algorithms developed during this project consisted of four elements: a seeker, a mothership UAS to tow the drogue, a passive towed drogue, and a ground station with associated communication structure. These elements are shown in Figure 8. 


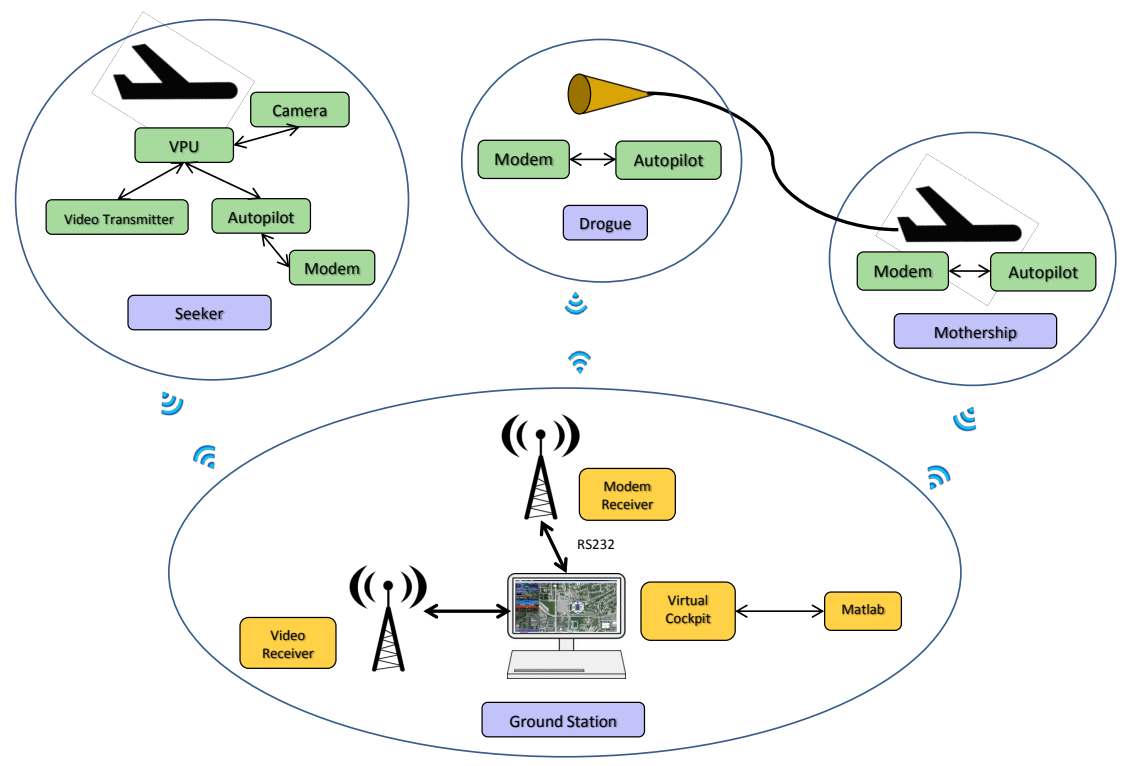

Fig. 8 Aerial rendezvous system hardware.

\section{Seeker}

The visual tracking method was tested with a seeker following a passively towed drogue. The aircraft used for the seeker is shown in Figure 9 (a). It is a $1.4 \mathrm{~m}$ wing span elastic poly propylene foam flying wing. The seeker is equipped with GPS, a Kestrel 2 autopilot, and a vision processing unit (VPU) that interfaces directly with the camera. The seeker was powered using a $5000 \mathrm{mAh}$ lithium polymer battery connected to a single $350 \mathrm{~W}$ Himax brushless motor. The seeker had a maximum flight time of $45 \mathrm{~min}$. The autopilot interfaces with the ground station through an RF digital modem. The ground station sends high-level commands to the autopilot and VPU and receives real-time vehicle telemetry from the autopilot as depicted in Figure 8. The seeker lateral and longitudinal guidance algorithms were implemented onboard the VPU. The VPU receives autopilot telemetry packets and sends command packets to the autopilot at $30 \mathrm{~Hz}$. The Kestrel autopilot loops run at $50 \mathrm{~Hz}$. For inner control loops we used the autopilot climb rate control loop, the airspeed control loop, and the roll angle control loop. The outer guidance loop controlled the inner loop by sending airspeed, roll angle, and climb rate commands to the autopilot. 
A digital camera was used in conjunction with the VPU. The fixed camera was mounted in the nose of the seeker and had a 78 deg field-of-view. Visual tracking techniques programmed on the VPU made it possible to manually designate user-selected airborne targets. The video feed was transmitted to the ground and displayed at the ground station. Using the ground station, the user manually selected the drogue or other targets that the UAS was commanded to follow.

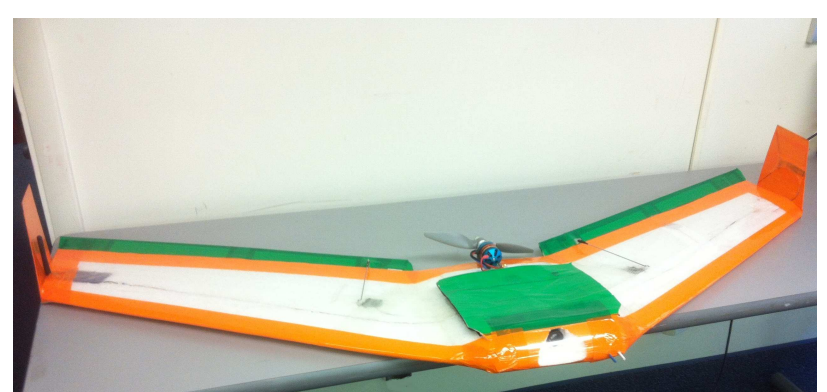

(a)

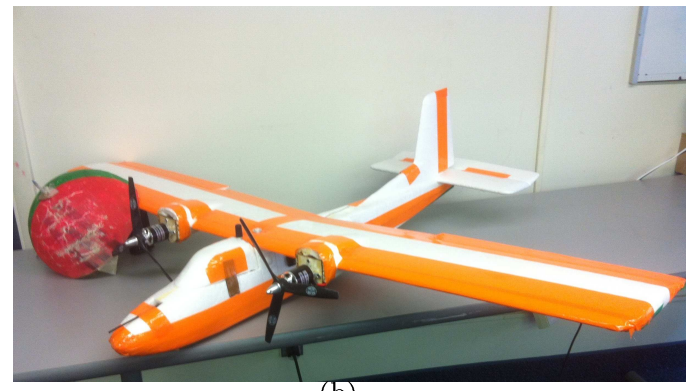

(b)

Fig. 9 (a) The model aircraft used as the seeker is a $1.4 \mathrm{~m}$ wingspan flying wing equipped with an autopilot, camera, and on-board vision processing unit. (b) Mothership and drogue. The drogue is a $30 \mathrm{~cm}$ diameter half-sphere towed using a nylon cable.

\section{Mothership}

The model aircraft used for the mothership is shown in Figure 9 (b) and is a $1.4 \mathrm{~m}$ wing span Multiplex Twin Star airframe equipped with a Kestrel 2 autopilot and modem to communicate with the ground station. The mothership was powered using two $5000 \mathrm{mAh}$ lithium polymer batteries connected to twin $910 \mathrm{~W}$ Turnigy motors typically using about $500 \mathrm{~W}$ each. When pulling the drogue, the mothership had a maximum flight time of $30 \mathrm{~min}$. The mothership control algorithms discussed in this paper were implemented in Matlab and run on the ground station computer. Mothership waypoint commands were broadcast from the ground station to the mothership.

\section{Drogue}

The $30 \mathrm{~cm}$ diameter hemisphere drogue used in this project was constructed of reinforced plastic as shown in Figure 9 (b). The drogue was equipped with a Kestrel 2 autopilot and modem for reporting its position and velocities to the ground station. The drogue GPS states were rebroadcast to the seeker. The drogue was passive with no controllable surfaces and it was attached to the 
mothership using an $85 \mathrm{~m}$ nylon cable.

\section{Ground Station}

The ground station was a desktop computer that interfaces to the autopilots on the mothership, drogue, and seeker, as well as the VPU on the seeker. The ground station allowed the operator to monitor the status of all three autopilots simultaneously and communicate with the VPU to change pursuit modes and designate airborne objects to be tracked by the VPU. The communications link with the autopilots was $115.2 \mathrm{~KB} / \mathrm{s}$. In addition, the desktop computer had Matlab installed to run the control algorithms for the mothership.

\section{B. Mothership waypoint generation and tracking}

The autopilot on the mothership receives waypoint commands and not a time-varying commanded trajectory. To produce the commanded waypoints, the differential flatness based trajectory planner described in Section II is used to compute a trajectory based on the desired drogue orbit and the current state of the mothership. The resulting trajectory, which roughly corresponds to one orbit, is then discretized into 361 waypoints and sent to the autopilot.

\section{Wind update strategy}

As explained in Section II, given a desired drogue orbit, the desired trajectory of the mothership depends on the current wind direction and magnitude. The autopilot uses measurements of ground speed (obtained from GPS), course angle (obtained from GPS), and airspeed (obtained from the pitot tube) to estimate the instantaneous direction and magnitude of the wind. However, due to gusts and the sensitivity of the sensors, the instantaneous estimate of the wind is noisy. However, a reasonably accurate estimate of the wind can be obtained by averaging the instantaneous estimate over one orbit period.

Therefore, the desired mothership orbit is updated once per orbit based on the average wind direction and magnitude. To facilitate update during flight, the desired trajectories of the mothership in different wind conditions were precalculated using different wind speeds with the assumed direction coming from the south. The precalculated trajectory is then rotated in the North-East 
plane to align with the actual wind direction. Each time the mothership crosses the half-plane defined by the actual wind direction, a new precomputed mothership orbit is used based on the estimated average wind speed.

\section{Trajectory tracking for mothership using desired drogue orbit with constant airspeed}

To facilitate the air-to-air rendezvous of the drogue and seeker in flight, a desired drogue orbit with constant airspeed and $(250 \mathrm{~m})$ radius was employed.

Using the desired drogue orbit shown in Figure 3 and the wind update strategy introduced previously, Figure 10 shows the flight test results using a desired drogue orbit with constant airspeed and a orbit radius of $250 \mathrm{~m}$. The desired mothership orbit was updated at time 20,100,180, $260 \mathrm{~s}$. It can be seen from Figure 10 (a) and (b) that the actual mothership path was able to follow the desired trajectory with small tracking error in three dimensions except for a deviation in the southwest corner. The altitude tracking result of the drogue shown in Figure 10 (b) illustrated oscillation with an average amplitude of approximately $10 \mathrm{~m}$ except for some large deviation. It can be seen from Figure 10 (c) and (d) that the waypoint following strategy works very well in manipulating the mothership to follow the desired position and airspeed. It can be seen from Figure 10 (d) that an obvious deviation of the horizontal tracking happened at time period $50-100 \mathrm{~s}$, which corresponded to the deviation in Figure 10 (a) at the southwest corner. The reason could be the large wind gust (see Figure 10 (f)) and the inherent communication lag between the autopilot and the combox in the muti-agent hardware structure. Figure 10 (e) shows that the amplitude of the oscillation of the drogue altitude hold within $10 m$ except for the large deviation at time $50-100 \mathrm{~s}$ which matches the results in Figure 10 (a) and (d). Figure 10 (f) shows the wind estimation in north-east frame.

\section{E. Air-to-Air Tracking}

Using the control method described in Section III, the flight trials were conducted in a build-up approach, beginning with tracking the mothership as the target before attempting to follow and rendezvous with the drogue. Both GPS and vision data were used as sensor inputs for the tracking algorithm. The nonlinear visual pursuit algorithm was first tested with the seeker tracking the mothership without the drogue as can be seen in Figure 11 (a). The seeker followed the mothership 


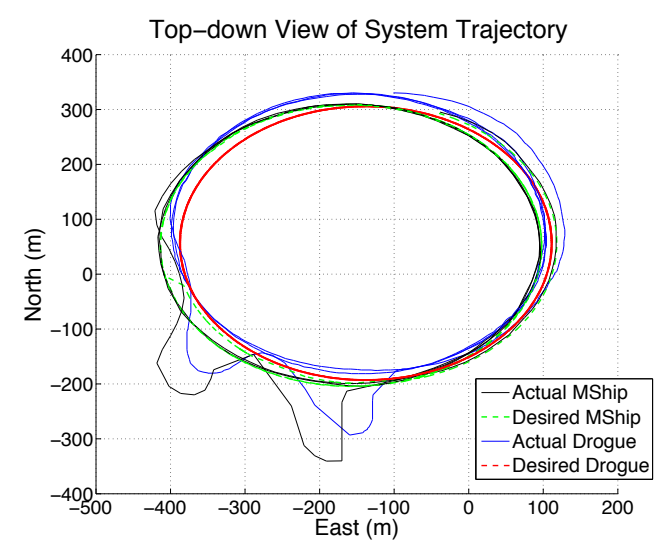

(a)
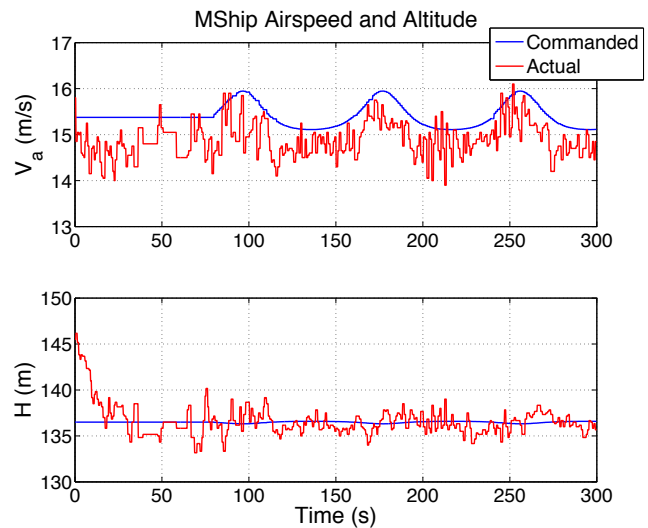

(c)

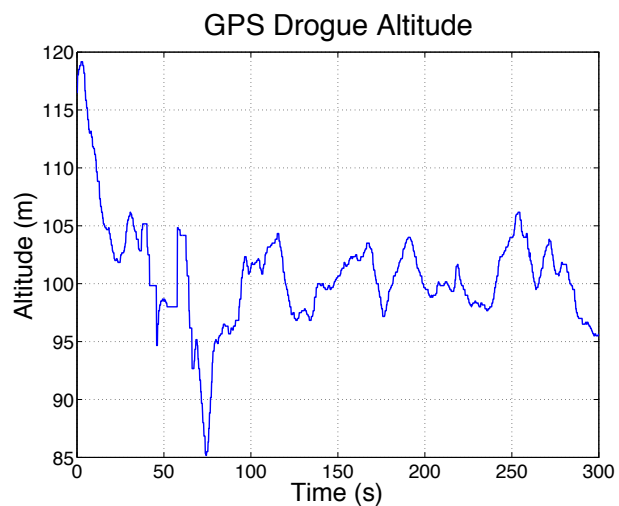

(e)

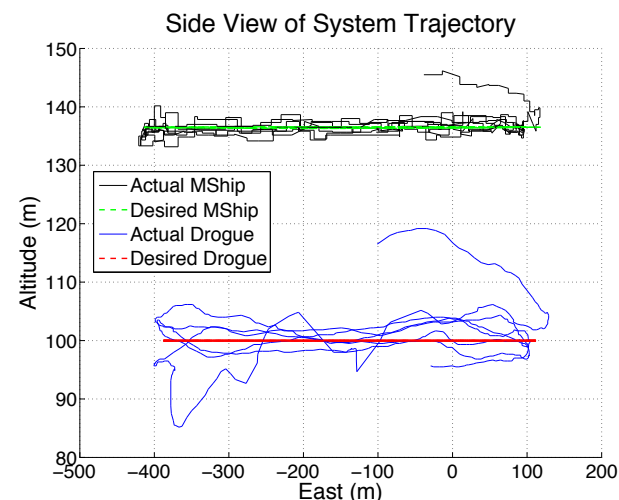

(b)
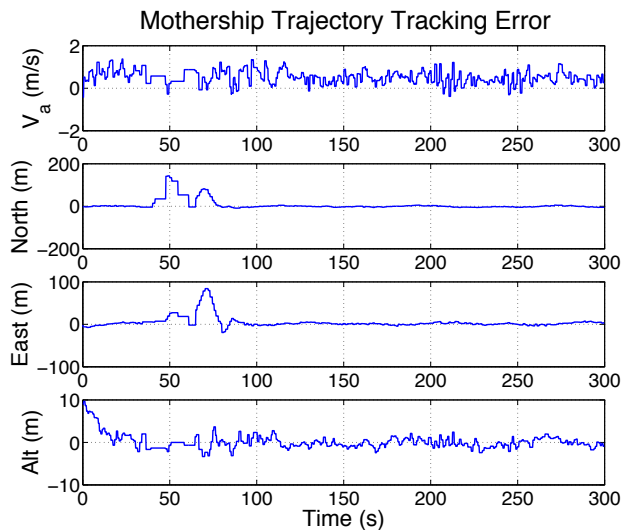

(d)
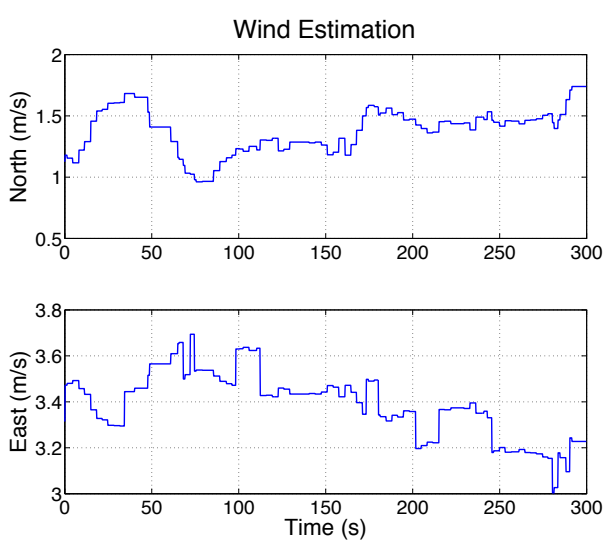

(f)

Fig. 10 Flight test results using the desired drogue orbit with constant airspeed. (a) Top-down view; (b) Side view; (c) Airspeed and altitude of the mothership; (d) Mothership tracking error; (e) Altitude deviations of the mothership; (f) Wind estimation.

at a nominal distance of $30 \mathrm{~m}$ and an altitude of $125 \mathrm{~m}$. Both vehicles began at approximately the same altitude. Therefore, the test primarily stressed the lateral tracking accuracy. The test was conducted such that when the seeker lost visual lock on the mothership, the algorithm reverted to 
using rebroadcast GPS position data from the mothership. Climb rate and roll angle were controlled according to (21) and (25).

The tracker sometimes lost track of the airborne target because of the target motion or changes in background color, even when the target remained within the camera FOV. This required the operator to sometimes rapidly redesignate the target location. When the vision track was lost, sensor data for tracking guidance reverted to receiving the GPS location of the airborne target as it was rebroadcast from the ground station. When using GPS data, the data was delayed by approximately $200 \mathrm{~ms}$ as the position data of the drogue was rebroadcast to the seeker through the ground station. The same guidance algorithm was used independent of whether the data was received from GPS or vision processing. The operator received visual feedback when vision tracking was engaged. Whenever the square designation box was visible, as can be seen in Figure 11 (b), the seeker was using vision data for guidance with no appreciable delay in the drogue position information.

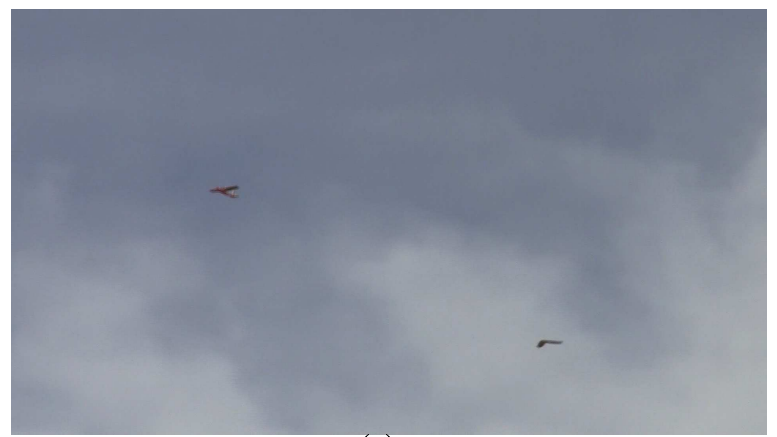

(a)

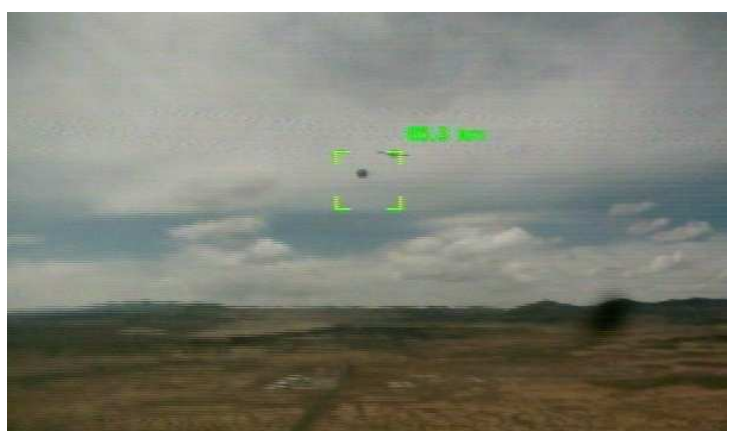

(b)

Fig. 11 (a) External video frame showing mothership and UAS in formation flight; (b) Single frame from UAS camera while following drogue. Drogue is visible in center of green acquisition box. Mothership is obscured by top right corner of acquisition box.

Figure 12 shows the seeker tracking and following the mothership from an average distance of $30 \mathrm{~m}$ over a $180 \mathrm{~s}$ time frame. The mothership is following a $250 \mathrm{~m}$ radius orbit and the seeker is using vision and GPS sensor data to follow it. With a 78 deg field-of-view lens, the line-of-sight angles that allowed the drogue to remain on the image plane were $\pm 39 \mathrm{deg}$. The visual position of the target in pixels is converted to line-of-sight angles according to (5) and (6) for direct comparison with tracking performance using GPS data. 
During this test, the winds were about $2 \mathrm{~m} / \mathrm{s}$ from the west. The altitude change over the course of the orbit was $\pm 10 \mathrm{~m}$ from the nominal altitude of $125 \mathrm{~m}$. The seeker lost visual lock four times during this test and was locked on for approximately 33 percent of the time. In Figure 12 (a), the line-of-sight errors when using GPS are plotted along with the line-of-sight errors when using vision. The vision data had a mean error from the centerline of $8.6 \mathrm{deg}$ and the GPS data had a mean error of $12.7 \mathrm{deg}$. When using vision data, the visual pursuit method had a mean error 32 percent less than when using GPS which can be attributed to the time delay and position uncertainty when using GPS. The mean commanded bank angle was $7.9 \mathrm{deg}$ and the mean commanded climb rate was $7.2 \mathrm{deg} / \mathrm{s}$. The distance between the seeker and the mothership was nominally $30 \mathrm{~m}$, however it varied between $15-50 \mathrm{~m}$ during the test as the closure algorithm (27) was also tested. The additional maneuvering accounts for the higher control inputs and increased scatter of the LOS angles when compared with the simulation results in Figure 7. Nevertheless, visual pursuit demonstrated excellent air-to-air tracking performance in a real-world flight environment.

\section{F. Rendezvous}

The culminating test of the vision rendezvous system brought all the pieces together. The mothership was flown towing a non-actuated hemispheric drogue on an flexible $85 \mathrm{~m}$ cable while executing trajectory tracking to keep the drogue orbit level. The seeker was flown using the visual pursuit algorithm to track, follow, and attempt to touch the airborne drogue. The drogue was towed in a $250 \mathrm{~m}$ radius circular orbit with an approximate airspeed of $15 \mathrm{~m}$. The seeker began the rendezvous attempt from a stable position $20-30 \mathrm{~m}$ behind the drogue. When the seeker had a good visual lock, the engage command was given from the ground station which commanded the seeker to close the distance to the drogue using (27). The seeker closure airspeed was $2 \mathrm{~m} / \mathrm{s}$ faster than the drogue airspeed. An example engagement is shown in Figure 13 . Winds were $2 \mathrm{~m} / \mathrm{s}$ from the west. The LOS angles to the drogue are shown in Figure 13 (a). The hardware limitations of the vision tracker mentioned previously are most evident as the seeker gets closer to the drogue. The sharp jumps in the LOS angles are a result of the guidance algorithm switching between vision data and GPS data as the seeker acquired and then lost visual track on the drogue. This phenomenon 


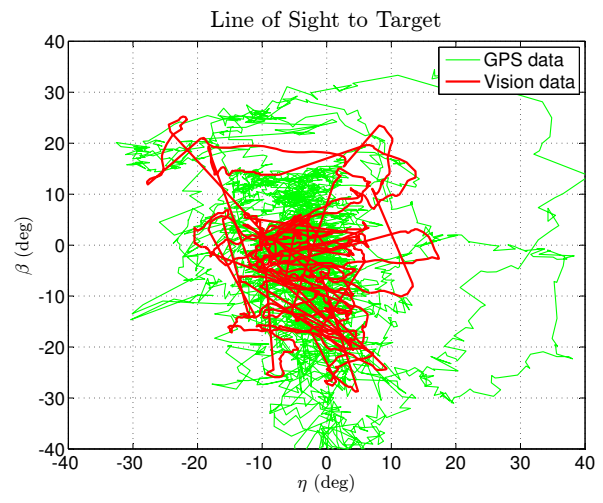

(a)

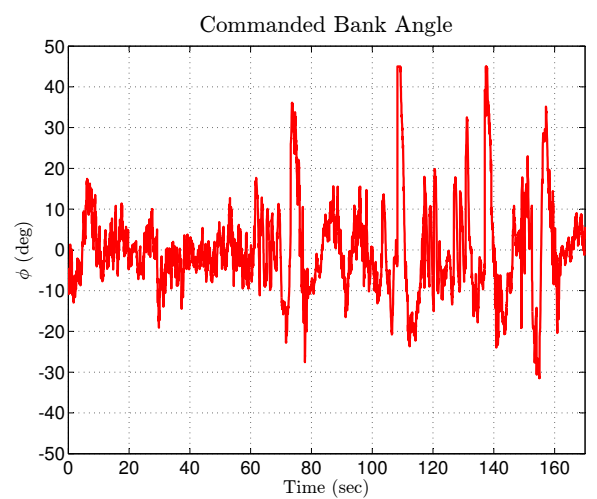

(c)

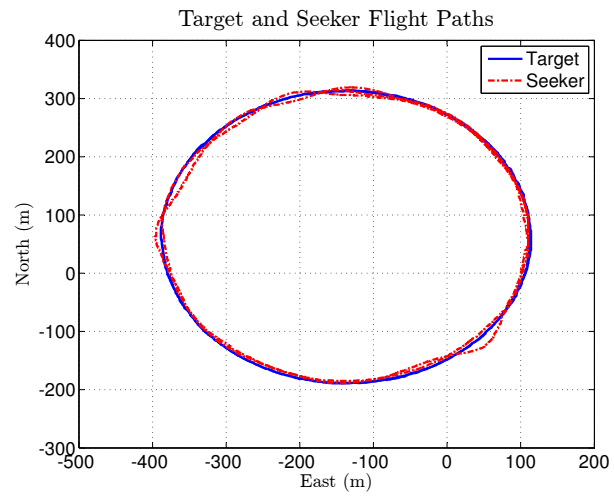

(b)

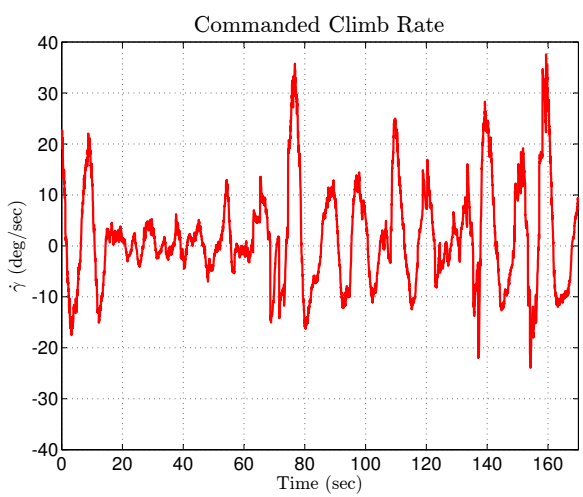

(d)

Fig. 12 (a) Line-of-sight error to the drogue vehicle based on GPS position (green) and vision data (red) for seeker vehicle using nonlinear visual guidance. Camera pixel data is converted to line-of-sight angles according to (5) and (6); (b) Seeker UAS and drogue UAS flight paths; (c) commanded roll angle; (d) commanded climb rate.

can more easily be seen in Figure 13 (b) where the regions of vision-based guidance and GPS-based guidance are overlayed on a plot of the separation distance between the seeker and the drogue. During this engagement the seeker passed by the drogue with its closest approach at $2.7 \mathrm{~m}$. The control inputs shown in Figure 13 (c) and (d) also show a correlation with transitions between vision and GPS data. In addition, these plots show an inherent weakness of vision-based control as it nears the target. Examining (21) and (25) we see that commanded bank angle and climb rate both are functions of the LOS distance $\rho$ in the denominator. We see from the data that at very close range to the target, the control inputs become large and eventually saturate. To account for this effect, the control gains, $K_{\phi}$ and $K_{\gamma}$, are scaled to zero as the seeker approaches the drogue. However, this 


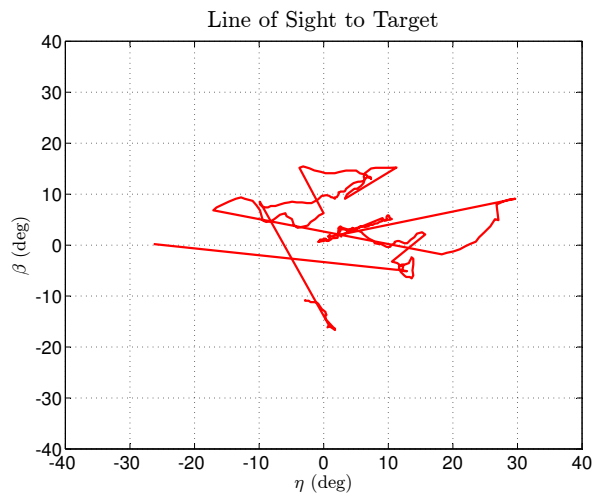

(a)

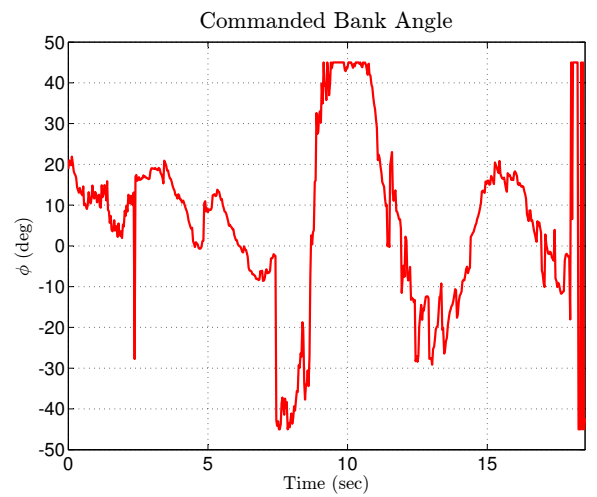

(c)

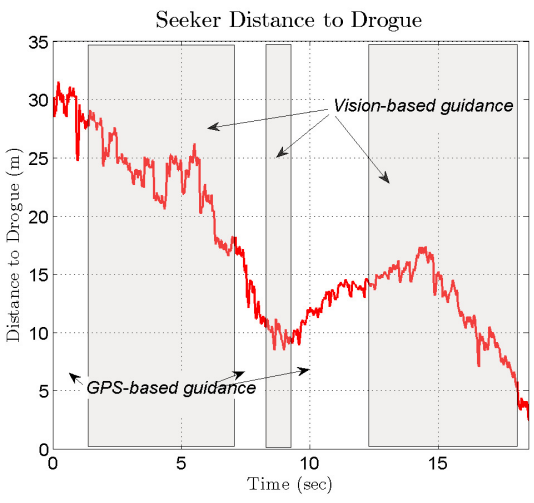

(b)

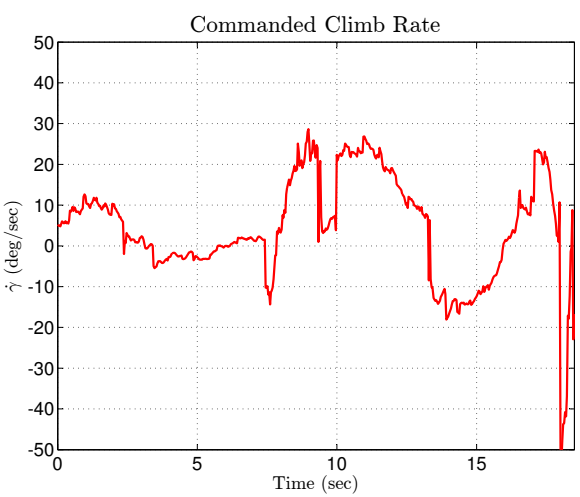

(d)

Fig. 13 Flight test results of the seeker closing on the drogue (a) Vision-based Line-of-sight error to the drogue. Camera pixel data converted to line-of-sight angles according to (5) and (6); (b) Seeker distance to drogue, time segments using vision guidance indicated by the shaded region, GPS data used at other times; (c) commanded roll angle; (d) commanded climb rate.

was not enough to prevent control saturation during the final half second of the engagement shown. This limitation is explained more completely in [33].

While we did succeed in hitting the target on some occasions, we could not do it consistently. Approaches within a few meters like the example shown were common. To improve end-game performance a more robust visual tracker is needed and control inputs must be frozen prior to reaching saturation just before hitting the drogue. 


\section{Conclusions}

Significant progress toward solving the aerial rendezvous problem was demonstrated during the aerial recovery project. In this paper we have shown in both simulation and open air flight testing the ability to control the orbit of a passively towed drogue in moderate wind conditions by manipulating the airspeed and trajectory of the mothership. The control method developed here produced drogue orbits that were level to the ground and circular and at airspeeds suitable for the slower seeker to track and approach the passive drogue.

We also developed a nonlinear visual pursuit method for the seeker to track the drogue and provide control inputs to allow it to autonomously fly in formation with the drogue and approach it to within a few meters. We demonstrated how to use a camera to obtain the line-of-sight to the drogue and the ability to control the lateral and longitudinal motion of the seeker.

Future work to produce a system capable of routine aerial docking requires development of a more robust vision tracker, increase in the stability of the drogue, and further development of vision tracking methods suitable for use in very close proximity to the target.

\section{Acknowledgments}

Research support for this work was provided by the Air Force Office of Scientific Research through the Small Business Technology Transfer Program, contract number FA9550-10-C-0041, and in cooperation with Lockheed Martin Procerus Technologies. This support is gratefully acknowledged. In addition, the authors would like to thank Mr. Neil Johnson from Lockheed Martin Procerus Technologies for his assistance in coding the methods developed in the paper for implementation on the VPU and for assisting in the flight trials.

\section{References}

[1] Sun, L., Beard, R. W., and Colton, M. B., "Motion planning and control for mothership-cable-drogue systems in Aerial Recovery of Micro Air Vehicles," American Control Conference, Baltimore, MD, USA, 2010 , pp. $2101-2106$.

[2] Sun, L. and Beard, R. W., "Towed-body Trajectory Tracking in Aerial Recovery of Micro Air Vehicle in the presence of Wind," American Control Conference, San Francisco, CA, USA, 2011, pp. 3209-3214. 
[3] Colton, M., Sun, L., Carlson, D., and Beard, R., "Multi-vehicle dynamics and control for aerial recovery of Micro Air Vehicles," Int. J. Vehicle Autonomous Systems, Vol. 9, 2011, pp. 78-107.

[4] Nichols, J., Ferrin, J., Owen, M., and McLain, T., "Vision-enhanced aerial rendezvous along elliptical paths," AIAA, Guidance, Navigation and Control Conference, Minneapolis, MN, USA, August 2012.

[5] Sun, L., Hedengren, J. D., and Beard, R. W., "Optimal Trajectory Generation using Model Predictive Control for Aerially Towed Cable Systems," AIAA Journal of Guidance Control and Dynamics, (in review).

[6] Wyllie, T., "Parachute Recovery for UAV systems," Aircraft Engineering and Aerospace Technology, Vol. 73, No. 6, 2001, pp. 542-551.

[7] Mullens, K., Burmeister, A., Wills, M., Stroumtsos, N., Denewiler, T., Thomas, K., and Stancliff, S., "Automated Launch, Recovery, and Refueling for Small Unmanned Aerial Vehicles," Mobile Robots XVII, Society of Photo-Optical Instrumentation Engineers, SPIE Proceedings Series, Vol. 5609, 2004, pp. 233-243.

[8] Kahn, A. D., "Vision-Based Recovery and Guidance for Small Unmanned Air Vehicles," AIAA Guidance, Navigation, and Control Conference, Toronto, Ontario Canada, August 2010.

[9] Skop, R. A. and Choo, Y., "The Configuration of a Cable Towed in a Circular Path," Journal of Aircraft, Vol. 8, No. 11, November 1971, pp. 856-862.

[10] Williams, P. and Trivailo, P., "Stability and Equilibrium of a Circularly-Towed Aerial Cable System with an Attached Wind-Sock," AIAA Atmospheric Flight Mechanics Conference and Exhibit, San Francisco, CA, August 2005, pp. 1-33.

[11] Choo, Y. and Casarella, M. J., "A Survey of Analytical Methods for Dynamic Simulation of Cable-Body Systems," Journal of Hydronautics, Vol. 7, No. 4, 1973, pp. 137-144.

[12] Chin, C., May, R., and Connell, H., "A numerical model of a towed cable-body system," ANZIAM Journal, Vol. 42, 2000, pp. C362-C384.

[13] Cochran, J. E. J., Innocenti, M., No, T. S., and Thukral, A., 'Dynamics and Control of Maneuverable Towed Flight Vehicles," JGCD, Vol. 15, No. 5, 1992, pp. 1245-1252.

[14] Henderson, J. F., Potjewyd, J., and Ireland, B., "The dynamics of an airborne towed target system with active control," Proceedings of the Institution of Mechanical Engineers, Part G: Journal of Aerospace Engineering, 1999.

[15] Sun, L., Beard, R. W., Colton, M. B., and McLain., T. W., 'Dynamics and Control of Cable-Drogue System in Aerial Recovery of Micro Air Vehicles Based on Gauss's Principle," American Control Conference, St. Louis, MO, USA, June 2009, pp. 4729-4734. 
[16] Trivailo, P., Sgarioto, D., and Blanksby, C., "Optimal Control of Aerial Tethers for Payload Rendezvous," Proceedings of the 5th Asian Control Conference, 2004, pp. 396-404.

[17] Williams, P., "Optimal terrain-following for towed-aerial-cable sensors," Multibody Syst Dyn, Vol. 16, 2006, pp. 351-374.

[18] Sun, L. and Beard, R. W., "Towed Body Altitude Stabilization and States Estimation in Aerial Recovery of Micro Air Vehicles," AIAA, Guidance, Navigation and Control Conference, Toronto, Ontario Canada, August 2010.

[19] Murray, R., "Trajectory Generation For a Towed Cable System Using Differential Flatness," 13th Triennial World Congress of the International Federation of Automatic Control, 1996, pp. 395-400.

[20] Brushwood, D. L., Olsont, A. P., and Smyth, J. M., "The E-6A Orbit Improvement System and its Effect Upon LTWA Verticality," 1998.

[21] Williams, P., Sgarioto, D., and Trivai, P., "Motion Planning for an Aerial-Towed Cable System," AIAA Guidance, Navigation and Control Conference and Exhibit, August 2005.

[22] Williams, P. and Trivailo, P., 'Dynamics of Circularly Towed Cable Systems, Part 2: Transitional Flight and Deployment Control," AIAA Journal of Guidance Control and Dynamics, Vol. 30, No. 3, May-June 2007, pp. 766-779.

[23] Ferrin, J., Nichols, J., and McLain, T., "Design and control of a maneuverable towed aerial vehicle," AIAA, Guidance, Navigation and Control Conference, Minneapolis, MN, USA, August 2012.

[24] Hover, F. S., "Experiments in Dynamic Positioning of a Towed Pipe," OCEANS '93. Engineering in Harmony with Ocean, Vol. 3, Victoria, BC, Canada, Oct 1993, pp. III484 - III490.

[25] Fliess, M., Levine, J., Martin, P., and Rouchon, P., "Flatness and defect of non-linear systems: introductory theory and examples," International Journal of Control, Vol. 61, No. 6, 1995, pp. 1327-1361.

[26] Frew, E. W., Lawrence, D. A., Dixon, C., Elston, J., and Pisano, W. J., "Lyapunov Guidance Vector Fields for Unmanned Aircraft Applications," Proc. American Control Conf. ACC '07, 2007, pp. 371376.

[27] Goncalves, V. M., Pimenta, L. C. A., Maia, C. A., Dutra, B. C. O., and Pereira, G. A. S., "Vector Fields for Robot Navigation Along Time-Varying Curves in n-Dimensions," IEEE Transactions on Robotics, Vol. 26, No. 4, 2010, pp. 647-659.

[28] Park, S., Deyst, J., and How, J. P., "Performance and Lyapunov stability of a nonlinear path-following guidance method," Journal of Guidance, Control, and Dynamics, Vol. 30, No. 6, November-December 2007, pp. 1718-1728.

[29] Stepanyan, V.and Hovakimyan, N., "Visual Tracking of a Maneuvering Target," Journal of Guidance, 
Control, and Dyanmics, Vol. 31, 2008, pp. 66-80.

[30] Saunders, J. and Beard, R. W., "Visual Tracking in Wind with Field of View Constraints," International Journal of Micro Air Vehicles, Vol. 3, No. 3, September 2011, pp. 169-182.

[31] Beard, R. W. and McLain, T. W., Small Unmanned Aircraft: Theory and Practice, Princeton University Press, 2012.

[32] Khalil, H. K., Nonlinear Systems, Prentice Hall, Upper Saddle River, NJ, 3rd ed., 2002.

[33] Nichols, J. W. and McLain, T., "A nonlinear guidance law for visual pursuit of a cooperative aerial target in wind," (to be submitted), 2013. 